\title{
RTV Silicone Rubber Coatings for Outdoor Insulators: A Concise Review of Some Factors Affecting their Behavior and Some Comments
}

\author{
R. Sarathi ${ }^{1}$ and M. G. Danikas ${ }^{2, *}$ \\ ${ }^{1}$ Indian Institute of Technology Madras, Department of Electrical Engineering, High Voltage Laboratory, Chennai, India \\ ${ }^{2}$ Democritus University of Thrace, Department of Electrical and Computer Engineering, Power Systems Laboratory, 67100 Xanthi, \\ Greece
}

Received 17 February 2021; Accepted 9 April 2021

\begin{abstract}
Traditional outdoor insulators are made of glass and porcelain. However, although such insulators have been used for many decades, they present some drawbacks. Glass and porcelain insulators seem to be more prone to surface discharges and flashover when they age and water droplets are more likely to spread on their surface, causing thus dry zones and consequently conditions for surface discharging and flashover. Room Temperature Vulcanized (RTV) coatings spayed on the aforementioned traditional insulators seem to remedy such problems because such coatings increase the hydrophobicity. In this paper, a short review on RTV coatings is given together with some thoughts and comments regarding the so-called early stage of aging.
\end{abstract}

Keywords: room temperature vulcanized silicone rubber coatings (RTV coatings), outdoor insulators, hydrophobicity, contact angle, leakage currents, low molecular weight fluid

\section{Introduction}

Glass and porcelain insulators have been traditionally used for many decades [1]. However, these insulators present some serious drawbacks regarding their behavior w.r.t. pollution, surface discharging and flashover [2]. Silicone rubber (SiR), being a polymeric material, presents good hydrophobic properties and as such it has been used both as a full insulator as well as a coating on the traditional outdoor insulators. Although SiR insulators present certain advantages compared with glass and porcelain insulators (e.g., lesser weight, resistance to vandalism, hydrophobicity, reduced dimensions, limited right of way passage), they also have - being polymeric materials - some problems, such as gradual deterioration due to tracking and erosion of the weathersheds and exposure and therefore sensitivity to discharges [3 - 5].

Alternatively, Room Temperature Vulcanized (RTV) SiR coatings have been sprayed on the surface of either glass or porcelain insulators, improving thus their electrical behavior [3]. RTV SiR coatings are known to possess excellent surface resistance to chemicals, corona discharge, thermal degradation and ultraviolet radiation [6]. The use of RTV SiR coatings to glass or porcelain insulators can possibly eliminate the need for the frequent maintenance, thereby decreasing the maintenance costs. Hence, RTV SiR coatings are well established as a maintenance product possessing high withstand capability especially in case of harsh environments like seacoast environment and industrial environment, because of their effectiveness in preventing outages caused by the contamination of the insulator surface due to these harsh environments [7]. Also, IEEE has developed a standard for

*E-mail address: mdanikas@ee.duth.gr

ISSN: 1791-2377 @ 2021 School of Science, IHU. All rights reserved. doi:10.25103/jestr.141.19 the application, maintenance and evaluation of RTV SiR coatings [8]. Silicone rubber imparts its hydrophobic property to the surface of glass or porcelain insulators rendering them more surface discharge resistant and, consequently, less prone to suffer flashover. As was reported before, "[as the SiR coating imparts its hydrophobicity to the surface of glass/porcelain insulators]" the formation of continuous water layers and the occurrence of leakage currents on the surface of insulators is prohibited, resulting in an increase of their flashover voltage" [9].

In the context of the present paper, no effort will be made to encompass the whole problematic of the SiR insulators [1012]. The present concise review will only tackle questions and problems relevant only to SiR coatings of glass/porcelain insulators. Some comments regarding the recovery of hydrophobicity of the SiR coatings will be made. Moreover, some thoughts on the so-called early stage of aging will be offered.

\section{Recovery of Hydrophobicity}

RTV coatings are no different from the SiR insulators regarding the mechanism of recovery of hydrophobicity. Relatively recently, some researchers have studied the hydrophobicity transfer of RTV coatings based on modification of absorption and cohesion theory and have indicated that the hydrophobicity transfer of RTV coatings is dependent on factors such as temperature, degree of cross linking, silicone rubber ingredients, content of the soluble salt and type of contamination [13]. In wet conditions, surface discharges cause dry band arcing and heat and - probably bond scission. Lower molecular weight (LMW) polydimethylsiloxane (PDMS) oligomers tend to be formed as a result of the heat. Smaller molecules are formed 
concomitant with crosslinking of the remaining body of the polymer at the surface. Such oligomers, under certain conditions, may diffuse to the surface of the coating as erosion occurs [14]. As was noted, possible chemical alterations due to heat from dry band arcing are, 1) instantaneous chemical dissociation of the surface at very high temperatures, and 2) slow dissociation through chemical reactions due to conduction of heat into the coating (scission and interchange of bonding or of chains, hydrolysis of siloxane bonds and hydrocarbon groups, oxidation of hydrocarbon groups and crosslinking of siloxane bond, pyrolysis) $[3,15,16]$.

A great advantage of RTV coatings is that they can be applied to already existing insulators, i.e. there is no need for replacement of insulators already in service. RTV coatings can be applied after adequate cleaning of the already existing insulators. Such coatings can offer a long-term solution [17, 18]. This, however, does not imply that RTV coatings do not have their own limitations. They can deteriorate in the presence of discharges.

\section{RTV Coating Composition and Thickness}

RTV (Room Temperature Vulcanizing) process is involved in the conversion of polymer or rubber into a long-lasting material. RTV SiR coating is a liquid polymer layer that vulcanize inside a flexible rubber layer when exposed to moisture [19]. As was noted, RTV coatings consist of a polydimethylsiloxane (PDMS) polymer, a reinforcing filler, PDMS fluid, alumina trihydrate (ATH) filler, colorant pigment, a crosslinking agent, condensation catalyst and an adhesion promoter [19]. Of these components, ATH filler is an inorganic filler helping to reduce tracking and to increase erosion resistance, thereby providing the long-term ability in limiting the leakage current and preventing flashover [20]. The thickness of such coatings must not exceed $1 \mathrm{~mm}$ and it was reported that the optimum thickness is between 0.3 and $0.5 \mathrm{~mm}$. Thicker coatings increase the thermal resistance and, consequently, render more difficult the conduction of heat away from the insulator [19]. As was noted elsewhere, excessive thickness does not necessarily imply good adherence to the ceramic surface, while not enough coating may result in areas left uncoated [21]. In [21] was also noted that the two basic requirements for a satisfactory performance of RTV coatings is the lasting hydrophobicity and the resistance to erosion and to surface discharges as well as the coating process itself.

RTV coatings act more effectively in polluted conditions than in clean and dry conditions. As was noted, material composition and dielectric strength are the two vital factors determining the performance of an RTV coating [22]. As was reported before [19], the optimum RTV coating thickness lies between 0.3 and $0.5 \mathrm{~mm}$ since a coating of $0.339 \mathrm{~mm}$ thickness gives low roughness parameters whereas a coating of $0.533 \mathrm{~mm}$ thickness gives the minimum erosion [23]. In yet another study, the authors suggested an optimum thickness of $0.2 \mathrm{~mm}$ and they attributed it to the thermal characteristics of the material. They also pointed out that with such coatings the problem is not so much tracking but material erosion [24].

It is expected that the quantity of LMW fluid depends on coating thickness, i.e. its quantity is greater in thicker coatings than in thinner coatings. It is also expected that a thicker coating can maintain its hydrophobicity for a longer period of time than a thinner coating. However, as was pointed out in [19], a thicker coating may develop more intense discharges for the same applied electric stress than a thinner coating. Therefore, as was reported in earlier research, an optimum thickness may exist, which may be beneficial for a longer time [25]. As was noted above [19], ATH filler is one of the constituents of RTV coating. It was reported that smaller ATH particle fillers imply a longer expected lifetime of RTV coating because they give a better heat conduction and a smoother coating surface. It was reported that the optimum ATH particle filler is at $4.5 \mu \mathrm{m}$ [26]. (It should be noted here that ATH filler has some limitations, namely that it breaks down at $220^{\circ} \mathrm{C}$ in an irreversible dehydration whereas silica coatings also breakdown and loose mass but at $400^{\circ} \mathrm{C}$ and beyond. Moreover, silica filler is not sensitive to moisture uptake and forms chemical bonds with the host matrix thereby improving strength, reducing porosity and further improving adhesion to substrates [27]). The optimum RTV coating thickness was found to be at $0.38 \mathrm{~mm}$, agreeing this respect with later research $[19,23]$. It was remarked, however, that the lifetime of RTV coating depends on various factors, such as LMW content, rate of diffusion to the surface of LMW fluid, thermal conductivity, surface roughness, type of substrate, ATH particle size, amount of ATH, electric stress level, coating thickness and pollution conditions [26]. Thicknesses of RTV coatings between $0.3 \mathrm{~mm}$ and $0.6 \mathrm{~mm}$ were also reported in [28] and between $0.3 \mathrm{~mm}$ and $0.5 \mathrm{~mm}$ in $[29,30]$.

\section{RTV Coatings and Contact Angle}

Silicone rubber presents in general a contact angle that exceeds $90^{\circ}$. This has been noted quite early [3]. Given silicone rubber's hydrophobicity, such a large contact angle prevents somehow the spreading of water droplets on the insulating surface and thus renders more difficult arcing and flashover [3, 31, 32]. The contact angle of an RTV coating is inexorably linked to its recovery of hydrophobicity. The recovery in turn is dependent on the LMW fluid that is available in the coating. Soxhlet extraction provides a good method to determine the amount of LMW fluid left in a sample of RTV coating. It was shown that after several years of service and after an initial decrease of LMW fluid, there was an asymptotic trend showing a stabilization of the LMW fluid in the coating. Even under severe pollution, LMW fluid was present in the coating which means that such an asymptotic trend may be a reasonable criterion for the longevity of a coating [33]. The contact angle is influence by the chemical constitution of the RTV coating, and it was found that addition of silica in the composition improves the contact angle and the performance of RTV coating [34].

The contact angle results after salt-fog test have reflected a recovery of hydrophobicity on the RTV coated surface after aging [35]. The authors of [35] have mentioned that the time lapse taken for hydrophobicity recovery was around 5 hours. The reorientation of hydrophobic methyl groups towards the surface is reported as the main reason for the recovery of hydrophobicity.

Thermal cycling may have an effect on contact angle and especially on the transfer ability of LMW fluid to the surface of an RTV coating. According to [36], during thermal cycling treatment, more channels for transfer of LMW fluid may be formed and they may facilitate the evaporation and diffusion of LMW fluid leading to a competitive mechanism of the easier transfer of LMW fluid and the reduction of LMW fluid in the bulk. When the treatment time is short, the easier transfer for LMW silicone fluid dominates the transfer 
process because there are enough available LMW components. With the increase of the treatment time, the reduction of LMW silicone fluid is dominant. Consequently, - because of all these - there will be an effect on contact angle. Agreeing with [36], the researchers of [37] pointed out that a higher ambient temperature favors the transfer of hydrophobicity and the transfer of LMW fluid from bulk to pollutants greatly increases - and thus the contact angle when the temperature rises from $50^{\circ} \mathrm{C}$ to $55^{\circ} \mathrm{C}$.

Investigating superhydrophobic coating surfaces, some researchers found that by increasing the coating thickness the water droplet repellency decreases. They attributed this to the increasing smoothness of the surface by increasing thickness, which in turn renders easier the spreading of water droplets [38]. One, however, tends to believe that there may be some antagonistic factors between increasing thickness and because of it- larger quantities of LMW fluid available in the bulk of the coating [39]. The question of contact angle is intimately related to hydrophobicity recovery. If one considers the RTV coating as a "reservoir" of LMW fluid, what will be the pollution conditions which will render hydrophobicity very difficult or even impossible (and consequently with a smaller contact angle)? Is there a 'fatigue' process which will eventually make the RTV coating surface less hydrophobic? [40] Such questions are pertinent in view of earlier work [41, 42], where there were suggestions that such a 'fatigue' process may actually exist.

\section{RTV Coatings and Leakage Currents}

Leakage currents are closely linked to the formation of dry zones, surface deterioration as well as to the process of the final flashover $[2,43]$. It is true that final flashover must be expected when there is a maximum leakage current [44]. Leakage current values depend on the variations of ambient conditions and the pollution accumulated [45]. Increasing levels of leakage current can be measured as the pollution accumulation increases over the insulators [45].

The leakage current development is suppressed on RTV coated insulating surfaces compared to uncoated surfaces due to reorientation of hydrophobic methyl groups towards the surface [15]. This suppression of leakage current development is strongly influenced by the environmental conditions. The coated surfaces in various environments will reorientate according to their local micro-environment for minimizing the interfacial-free energy with the surrounding water [46]. Leakage current propagation results in dry band arcing and tends to accelerate the aging of coatings [15]. During dry band arcing, thermal energy penetrates into the bulk of the coating and break the side and main chains of the PDMS molecule. The broken side chains result in low molecular weight silicones or the short PDMS molecules which tend to diffuse towards the surface. Even after the RTV SiR coating completely loses its hydrophobicity, it recovers after a short time period and suppress the development of leakage current. This is because of the reorientation of the hydrophobic methyl group towards the surface and the diffusion of low molecular weight PDMS from the bulk to the surface [47]. Hence, RTV SiR coatings with their ability to suppress leakage current, help in inhibiting the occurrence of flashover phenomenon [48].

RTV coatings have a beneficial effect on leakage currents since they reduce their values significantly. A comparison between a $150 \mathrm{kV}$ porcelain insulator and a $150 \mathrm{kV}$ with RTV coating porcelain insulator reveals that the latter has leakage currents values about 10-15 times smaller than the former [49, 50]. It is noted, however, in $[49,50]$ that RTV coatings in demanding coastal conditions have a useful lifetime of at least 5 years. Investigating the effect of RTV coatings, other researchers reported that RTV coated insulators withstood much higher levels of contamination when compared with porcelain. Moreover, the recorded flashover voltage - with RTV coating - was about $20 \mathrm{kV}$ higher for the $230 \mathrm{kV}$ class insulators as well as for the $69 \mathrm{kV}$ class insulators at different operating voltages and for the range of ESDD (Equivalent Salt deposit Density) levels of $0.1 \mathrm{mg} / \mathrm{cm}^{2}$ up to $0.7 \mathrm{mg} / \mathrm{cm}^{2}$ [51]. Yet, other researchers reached more or less the same conclusions, namely that coated insulators offer smaller leakage currents for a range of voltages and consequently higher flashover voltages than non-coated insulators [52]. In [52], it was also reported that the leakage current depends on the insulator surface condition and that the leakage current waveforms were strongly distorted from the sinus wave due to the presence of harmonic components especially $5^{\text {th }}$ and $7^{\text {th }}$ components as results of the non-linear behavior of the insulator. As was noted before, the distorted leakage current waveform is also due to the presence of discharges on the insulator surface and especially during dry band arcing [53]. In conjunction to [53], it has been much earlier reported that with salt and mineral deposits which are formed during dry band arcing in a salt-fog environment, the development of leakage current is not only dependent on the temporary loss of hydrophobicity but also on the extent of the deposited layer, i.e. on the surface condition [54]. Reference [55] suggests a somehow more cautious approach regarding RTV coated insulators for $200 \mathrm{kV}$ DC lines. However, their study, although it suggests a rising of leakage current with time, it does not discourage from the use of RTV coating for HVDC lines. In agreement with previous studies, [56] reported that the energy loss in RTV coated insulators is about $59-66 \%$ to that of porcelain insulators (as energy loss is the energy dissipated during a certain period of time and is given as the integral of the voltage applied across the insulator in $\mathrm{kV}$ and the time varying leakage current flowing on the insulator surface in $\mathrm{mA}$ ). This advantage was attributed to the suppression of leakage current on the RTV coated insulator. Moreover, in [56] is pointed out that even when the hydrophobicity of the RTV coated insulator is temporarily lost, it does not permit complete wetting of the surface and therefore the flow of leakage current is less as compared to a completely hydrophilic porcelain insulator.

In a further extension of their previous work, some researchers investigated post-pin-RTV silicone rubber coated insulator and non-coated ceramic insulator for kaolin-salt polluted under clean fog at applied voltages of $10 \mathrm{kV}, 40 \mathrm{kV}$ and $60 \mathrm{kV}$ in laboratory conditions [57]. They observed that the leakage current waveform was symmetrical at both polarities and that the coated insulator was far superior to the non-coated insulator regarding the recorded leakage currents. Similar observations have been made in [58], where it was also reported that the leakage current behavior depends on the season during which measurements are performed, in other words on precipitation and condensation. It was also remarked that the performance of the RTV silicone rubber coated insulators was remarkably superior to the corresponding performance of the non-coated insulators, although neither washing nor any other maintenance procedure has been performed to the coated insulators since the coatings application. In yet another study by the same research group it was noted that the coating ability to suppress the surface activity - and the leakage current activity - is 
strongly correlated to the hydrophobicity recovery process [59]. In an earlier study, both the limitations of the ATH filler as well as the beneficial effects of the RTV coatings were shown [60]. In that, reference [60] is in agreement with [26]. The authors of [60] showed that the reduction of leakage current does not depend on filler level in the range of 0 to $50 \%$ wt, whereas with $60 \%$ wt RTV coatings failures were observed because of poor coating preparation. All in all, however, insulators with RTV silicone rubber coatings indicated a better performance than uncoated insulators regarding the leakage currents.

\section{RTV Silicone Rubber Coatings: How Long Can Hydrophobicity Endure?}

In [59], it is mentioned that the optimum thickness of RTV silicone rubber coating is $0.38 \mathrm{~mm}$. In other studies, the thickness varies between $0.3 \mathrm{~mm}$ and $0.5 \mathrm{~mm}[19,23]$. No matter the slight variations between the different researchers, the truth is that the thickness is limited to some tenths of one $\mathrm{mm}$. The question which may well be asked is for how longgiven the limited thickness - an RTV coating may generate hydrophobicity, i.e. for how long the LMW fluid can be diffused onto the surface in order to encapsulate foreign pollutants. Studies carried out on the loss and recovery of hydrophobicity point out that hydrophobicity may be temporarily lost during outdoor service but the lost hydrophobicity can be restored after a certain period of time. Polluted RTV coating surfaces may recover hydrophobicity after some longer period than clean RTV surfaces. Hydrophobicity is temporarily lost because of some chemical reaction [61].

However, a question remains as to - depending on pollution and other factors - when a coating may recover its hydrophobicity. As mentioned, RTV coatings depend on a number of factors [19]. Nevertheless, it is reasonable to assume that a thicker coating (i.e., with more available LMW fluid) will also be subjected to more severe discharges than a thinner coating for the same applied electric stress [9]. In other words, there is a number of antagonizing factors at work regarding the LMW fluid which will eventually come onto the surface of a coating. On a laboratory level, the content of the LMW fluid decreased with increasing duration of the test in an energized salt-fog chamber, something that may be attributed to the creation of dry zones and dry band arcing, which are more likely to form for longer test times [62]. On the other hand, the content of LMW fluid increased with increasing recovery time in air after the test in the energized salt-fog chamber, possibly because of the diffusion of silicone fluid from the bulk of the coating to its surface during recovery time [63]. The aforementioned diffusion of LMW fluid is usually formulated according to the following equation:

$\mathrm{M}_{\mathrm{t}} / \mathrm{M}_{0}=4\left(\mathrm{Dt} / \pi \mathrm{l}^{2}\right)^{1 / 2}$

where,

$M_{t}$ is the change in mass after time $t, M_{0}$ is the initial mass, $t$ is the time, D is the diffusion coefficient and 1 the RTV coating sample thickness [4]. In [9], it was pointed out that Eq. (1) assumes that the diffusion coefficient D is constant suggesting thus that if the weight loss is plotted a a function of $\mathrm{t}^{1 / 2}$ the graph will be a straight line 9as all other parameters in Eq. (1) are constant). This, however, is not always correct since a number of parameters come into play. Eq. (1) is based on Fick's law but the latter is not necessarily applicable because the LMW fluid diffusion is a complex phenomenon [9]. An alternative to Eq. (1) was developed and presented in [9]. However, the equations developed in [9] - both as twodimensional as well as three-dimensional expressions - are rather complicated.

To return to the initial question "how long can hydrophobicity endure?" in a RTV silicone rubber coating, we think the answer is not an easy one. It depends, among others, on coating thickness, on the quality of adhesion of the coating on the ceramic surface, on pollution conditions, on the service electric stresses, on possible mechanical/thermal effects and on the chemical and morphological structure of the coating [64]. This is certainly a question in need of an answer since RTV coatings find applications in more and more demanding conditions [65].

\section{Some Further Comments and Proposals for Future Research}

Some work on indoor insulation regarding the 'early stage of aging' was reported in various publications [66-69]. The 'early stage of aging' may give ample warning as to the state of an insulation and is characterized by some elementary chemical deterioration and the set-in of micro-discharges. Detection of the 'early stage of aging' is of importance for the monitoring of insulation systems. Such observations were not only confined to indoor insulation but also to outdoor insulation, as some earlier research has shown [70, 71]. It would be interesting if part of the work being done would concentrate also on some 'early aging phenomena' regarding the RTV coatings. This would probably help in the direction of longevity of such coatings as well as to better understand the workings of hydrophobicity recovery.

In the context of the present concise review, no reference was made to the influence of corona discharges on hydrophobicity and its possibility of recovery. The beneficial effects as well as relevant questions concerning the RTV silicone rubber coatings should also be thoroughly investigated regarding corona discharges since it was reported that the application of RTV silicone rubber coatings reduce the electric field stress on the cap and the pin regions of the insulator [72]. Furthermore, an analysis of RTV silicone rubber coating surface deterioration, contact angle variation and diffusion of LMW fluid onto the surface under different voltage profiles should be done in view of earlier work [73].

Considerable work has been done on porcelain, glass and composite SiR insulators in tropical areas. The influence, among others, of algae was studied. It has been pointed out that although porcelain and glass insulators show increased levels of leakage currents and diminishing flashover voltages in the presence of algae, $\mathrm{SiR}$ insulators indicated a better performance, although the latter were also affected by algae [74]. A possible future work would be to further investigate the influence of algae on RTV coated insulators. Moreover and in view of modern techniques (such as visible spectral imaging and laser-induced breakdown spectroscopy), relevant work must continue regarding the detection of severity of defects on the surface of RTV coated insulators $[75,76]$, as well as on the uniform spraying of RTV coatings on an insulator surface $[19,77]$. Last but - certainly not least, continuing efforts must be undertaken in order to further investigate the addition of nanoparticles into RTV coatings. As polymer nanocomposites show a most promising 
prospect for various high voltage applications [78], further efforts should concentrate on how to improve the long term performance of RTV silicone rubber coatings with nanoparticles in different pollution environments [80].

\section{Conclusions}

Some aspects of the RTV silicone rubber coatings have been studied in the context of this short review. Aspects, such as RTV composition, the possibility of hydrophobicity recovery, contact angle and the crucial role of leakage currents have been referred to. Certain problems of RTV silicone rubber coatings, such as the optimum thickness of such a coating, have been thoroughly studied and solved. One of the tantalizing questions is the problem of duration of hydrophobicity in such thin coatings, i.e of the continuing possibility of LMW fluid diffusion onto the surface of the RTV coating and its formulation since the present approach based on Fick's law - is not adequate. In view of the advent of polymer nanocomposites in the recent decades, more effort must be undertaken in order to further improve the performance of the RTV coatings.

This is an Open Access article distributed under the terms of the Creative Commons Attribution License.

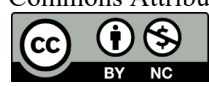

\section{References}

1. T. J. Gallagher, A. J. Pearmain, "High Voltage: Measurement, Testing and Design", Eds. John Wiley \& Sons, New York, USA, 1983

2. D. Kind, H. Kaerner, "High-Voltage Insulation Technology", Eds. Friedr. Vieweg \& Son, Braunschweig, Germany, 1985

3. R. S. Gorur, "High voltage insulation technology", Control and Dynamic Systems, Vol. 44, pp. 131-191, 1991

4. W. T. Starr, "Polymeric outdoor insulation", IEEE Transactions on ElectricalInsulation, Vol. 25, No. 1, pp. 125-136, 1990

5. J. S. T. Looms, "Insulators for High Voltages", Eds. Peter Peregrinus, London, UK, 1988

6. E. A. Cherney, A. El-Hag, S. Li, R. S. Gorur, L. Meyer, I. Ramirez, M. Marzinotto, J. M. George. "RTV silicone rubber pre-coated ceramic insulators for transmission lines", IEEE Transactions on Dielectrics and Electrical Insulation, Vol. 20, No. 1, pp. 237-244, 2013

7. G. Zhicheng and H. Zhidong. "The developments of room temperature vulcanized silicone rubber coating and its application in China", IEEE/PES Transmission and Distribution Conference and Exhibition, vol. 3, pp. 2203-2206. 2002

8. IEEE Std 1523, "IEEE Guide for the Application, Maintenance, and Evaluation of Room Temperature Vulcanizing (RTV) Silicone Rubber Coating for Outdoor Ceramic Insulators", 2002

9. A. Theodoridis, M. G. Danikas, J. Soulis, "Room temperature vulcanized (RTV) silicone rubber coatings on glass and porcelain insulators: An effort to model their behavior under contaminated conditions", Journal of Electrical Engineering, Vol. 52, No. 3-4, pp. 63-67, 2001

10. J. P. Reynders, I. R. Jandrell, S. M. Reynders, "Review of aging and recovery ofsilicone rubber insulation for outdoor use", IEEE Transactions on Dielectrics and Electrical Insulation, Vol. 6, No. 5, pp. 620-631, 1999

11. M. Amin, M. Izadi, M. Akbar, S. Amin, "Hydrophobicity of silicone rubber used for outdoor insulation (An overview)", Reviews on Advanced Materials Science, Vol. 16, No. 1, pp. 10-26, 2007

12. D. Ghosh, D. Khastgir, "Degradation and stability of polymeric highvoltage insulators and prediction of their service life through environmental and accelerated aging processes", ACS Omega, Vol. 3, pp. 11317-11330, 2018

13. Z. Jia, H. Gao, Z. Guan, L. Wang, J. Yang. "Study on hydrophobicity transfer of RTV coatings based on a modification of absorption and cohesion theory", IEEE Transactions on Dielectrics and Electrical Insulation, Vol. 13, No. 6, pp. 1317-1324, 2006

14. S. H. Kim, E. A. Cherney, R. Hackam, K. G. Rutherford, "Chemical changes at the surface of RTV silicone rubber coatings on insulators during dry-band arcing", IEEE Transactions on Dielectrics and Electrical Insulation, Vol. 1, No. 1, pp. 106-123, 1994

15. S. H. Kim, E. A. Cherney, R. Hackam, "Suppression mechanism of leakage current on the RTV coated porcelain and silicone rubber insulators", IEEETransactions on Power Delivery, Vol. 6, No. 4, pp. $1549-1556,1991$

16. S. H. Kim, E. A. Cherney, R. Hackam, "Effect of dry band arcing on the surface of RTV silicone rubber coatings", Conference Record of the IEEE InternationalSympum on Electrical Insulation, June 7-10, 1992, Baltimore, USA, pp.237-240
17. E. Kuffel, W. S. Zaengl, J. Kuffel, "High Voltage Engineering: Fundamentals", Eds. Newness (Butterworth-Heinemann), Oxford, UK, 2000

18. IEEE Dielectrics and Insulation Society Committee S-32-3R, "Round robin testing of RTV silicone rubber coating for outdoor insulation", IEEE Transactions on Power Delivery, Vol. 11, No. 4, pp. 1881-1887, 1996

19. S. H. K. Hamadi, M. Isa, S. N. Md Arshad, Hashim, M. Othman, "Review on RTV silicone rubber coatings insulator for transmission lines”, IOP Conference Series: Materials Science and Engineering, 864, 6 pages, 2020, doi:10.1088/1757-899X/864/1/012188

20. R.S. Gorur, E.A. Cherney, R. Hackam, "Electrical Performance of Polymer Insulating Materials: Effect of Material and Filler Type", Annual Report on Conference on Electrical Insulation and Dielectric Phenomena, pp. 350-355, 1985

21. J.-M. George, "Specifying RTV silicone coatings for overhead transmission lines", INMR Magazine, https://www.inmr.com/specifying-rtv-silicone-coatings-overheadtransmission-lines/, 2021

22. F. A. Jamaludin, M. Z. A. Ab-Kadir, M. Izadi, N. Azis, J. Jasni, M. S. Abd-Rahman, "Effects of RTV coating on the electrical performance of polymerinsulator under lightning impulse voltage condition", PLoS One, Vol. 12, No. 11,doi: 10.1371/journal.pone.0187892, 2017

23. S. Ilhan, Z. Aslan, "Investigation on leakage current, erosion, and hydrophobicperformance of high-voltage insulator coatings of different thicknesses", TurkishJournal of Electrical Engineering \& Computer Sciences, Vol. 28, pp. 1197-1207,2020

24. J. P. Holtzhausen, K. Engelbrecht, P. Pieterse, "Inclined plane tests on RTV-silicone rubber coated porcelain and cyclo-aliphatic epoxy resin samples", https://citeseerx.ist.psu.edu/viewdoc/download?doi=10.1.1.575.504 0\&rep=rep1\&type=pdf, 2005

25. H. Deng, R. Hackam, "Electrical performance of RTV silicone rubber coating of different thicknesses on porcelain", IEEE Transactions on Power Delivery, Vol.12, No. 2, pp. 857-866, 1997

26. H. Deng, "Electrical performance of RTV silicone rubber coatings for H. V.outdoor insulators", M. Sc. Thesis, University of Windsor, Department of Electrical Engineering, Canada, 1996

27. N. Arora, "RTV silicone insulator coatings - Technical evaluation andperformance", Presentation at the department of Electrical Engineering, IndianInstitute of Technology Delhi, $2^{\text {nd }}$ November 2016

28. S. M. Braini, "Coatings for outdoor high voltage insulators", Ph. D. Thesis, Cardiff University, School of Engineering, 2013

29. "RTV silicone rubber coatings", https://www.pacificmicrosystems.co.in/rtv-silicone-rubbercoatings.html

30. D. Fauziah, H. Alfiadi, Rachmawati, Suwarno, "Performances of long-term coastal field aged silicone-coated ceramic insulators under clean and salt fogconditions", Proceedings of the 2017 International Conference on High VoltageEngineering and Power Systems, October 2-5, 2017, Bali, Indonesia, pp. 51-56

31. M. G. Danikas, "Ageing properties of silicone rubber materials used in highvoltage composite insulators", Journal of Electrical and Electronic Engineering(Australia), Vol. 15, pp. 193-202, 1995 
32. H. Deng, R. Hackam, "Low-molecular weight silicone fluid in RTV silicone rubber coatings", IEEE Transactions on Dielectrics and Electrical Insulation, Vol. 6, No. 1, pp. 84-94, 1999

33. J.-M. George, S. Prat, F. Virlogeux, "Ageing and degradation mechanisms ofsilicone polymers used for outdoor electrical insulation", Proceedings of the $19^{\text {th }}$ International Symposium on High Voltage Engineering, August 23-25, 2015,Pilsen, Czech Republic, 6 pages

34. H. Jazayeri, M. Ehsani, F. Farhang, "Study of silicone rubber coatings (RTV) role on improvement of ceramic insulators behavior in contaminated areas", Journal of Color Science and Technology, Vol. 2, No. 1, pp. 9-22, 2008

35. S. H. Kim, E. A. Cherney, R. Hackam. "The loss and recovery of hydrophobicity of RTV silicone rubber insulator coatings", IEEE Transactions on Power Delivery, Vol. 5, No. 3, pp. 1491-1500, 1990

36. X. Wen, X. Yuan, L. Lan, L. Hao, Y. Wang, S. Li, H. Lu, Z. Bao, "RTV siliconerubber degradation induced by temperature cycling", Energies, Vol. 10, 12 pages, doi:10.3390/en10071054, 2017

37. Z. Guan, K. Niu, G. Peng, F. Zhang, L. Wang, B. Lutz, "Hydrophobicity transferproperty of silicone rubber material", International Journal on Electrical Engineering and Informatics, Vol. 4, No. 2, pp. 261-275, 2012

38. S. A. Seyedmehdi, H. Zhang, J. Zhu, "Influence of production method, silicone type and thickness on silicone rubber superhydrophobic coatings", Progress in Organic Coatings, Vol. 90, pp. 291-295, 2016

39. M. G. Danikas, R. Hackam, "Low-molecular weight silicone fluid in RTV silicone rubber coatings", IEEE Transactions on Dielectrics and Electrical Insulation, Vol. 7, No. 3, pp. 461-462, 2000

40. M. G. Danikas, S. M. Gubanski, "Experience with the Merry-goround test",IEEE Transactions on Electrical Insulation, Vol. 27, No. 5, pp. 1058-1060, 1992

41. A. E. Vlastos, S. M. Gubanski, "Surface structural changes of naturally agedsilicone rubber and EPDM composite insulators", IEEE Transactions on Power Delivery, Vol. 6, No. 2, pp. 888-900, 1991

42. S. M. Gubanski, A. E. Vlastos, "Wettability of naturally aged silicone rubber and EPDM composite insulators", IEEE Transactions on Power Delivery, Vol. 5, No.4, 2030-2038, 1990

43. F. Obenaus, "Fremdschichtueberschlag und Kriechweglaenge", Elektrotechnik,Vol. 4, pp. 135-137, 1958

44. M. P. Verma, "Die quantitative Erfassung von Fremdschichteinfluesse", ETZ-A, Vol. 97, No. 5, pp. 281-285, 1976

45. J. L. Fierro-Chavez, I. Ramirez-Vazquez, G. Montoya-Tena, "Online leakagecurrent monitoring of $400 \mathrm{kV}$ insulator strings in polluted areas", IEE Proceedings on Generation, Transmission and Distribution, Vol. 41, No. 6, pp.560-564, 1996

46. J. D. Andrade, "Polymer surface and interface dynamics: An introduction", In: Polymer Surface Dynamics, Eds. Springer US, pp. $1-8,1988$

47. M. J. Owen, T. M. Gentle, T. Orbeck, D. E. Williams. "Dynamic wettability of hydrophobic polymers", In: Polymer Surface Dynamics, Eds. Springer US, pp. 101-110, 1988

48. J. Hall, T. Orbeck, "RTV Protective Coating for Porcelain Insulators", IEEE/ PES 82 SM363-0, July 18-23, 1982

49. K. Siderakis, E. Thalassinakis, D. Pylarinos, I. Vitellas, "Substation pollution maintenance using RTV SIR coatings", Proceedings of World Congress on Insulators, Arresters and Bushings, May 10-13, 2009, Athens, Greece, 14 pages

50. K. Siderakis, D. Pylarinos, E. Thalassinakis, I. Vitellas, E. Pyrgioti, "Pollution maintenance techniques in coastal high voltage installations", Engineering, Technology \& Applied Science Research, Vol. 1, No. 1, pp. 1-7, 2011

51. R. Gorur, "Evaluation of station post porcelain insulators with Room Temperature Vulcanized (RTV) silicone rubber coating”, Final Project Report, PSERC Publication 12-19, Department of Electrical Engineering, Arizona State University, July 2012, 19 pages

52. Suwarno, A. B. Wibowo, "Increasing the performances of various types outdoor insulators by using RTV silicone rubber coating", International Journal on Electrical Engineering and Informatics, Vol. 4, No. 4, pp. 608-619, 2012

53. T. Suda, "Frequency characteristics of leakage current waveforms of an artificially polluted suspension insulator", IEEE Transactions on Dielectrics andElectrical Insulation, Vol. 8, No. 4, pp. 705-709, 2001

54. S.-H. Kim, "Electrical performance and surface analysis of RTV silicone rubbercoatings for H.V. outdoor insulators", Ph. D. Thesis, University of Windsor, Department of Electrical Engineering, Windsor, Ontario, Canada, 1992
55. M. Marzinotto, G. Lavecchia, M. R. Guarniere, A. Posati, M. Rebolini, J.-M. George, S. Prat, "DC-toughened glass insulators precoated with RTV siliconerubber- field returns from aged samples installed on HVDC lines", Proceedingsof the 2013 IEEE International Conference on Solid Dielectrics, June 30-Jule 4,2013, Bologna, Italy, pp. 170-173

56. V. Gholap, "Evaluation of room temperature vulcanized (RTV) silicone rubbercoated porcelain post insulators under contaminated conditions", M. Sc. Thesis,Arizona State University, 2013

57. Suwarno, A. Basuki, F. Lendy, Sumedi, "Improving outdoor insulator performances installed at coastal area using silicone rubber coating", Proceedings of the 2012 IEEE Conference on Condition Monitoring andDiagnosis, 23-27 September 2012, Bali, Indonesia, pp. 1143-1146

58. K. Siderakis, D. Agoris, "Performance of RTV silicone rubber coatings installedin coastal systems", Electric Power Systems Research, Vol. 78, pp. 248-254, 2008

59. K. Siderakis, D. Pylarinos, "Room temperature vulcanized silicone rubber coatings: Application in high voltage substations", in "Concise Encyclopedia of High Performance Silicones", edited by A. Tiwari and M. D. Soucek, Eds. Scrivener Publishing LLC, pp. 317,2014

60. S. Kumagai, M. Suzuki, N. Yoshimura, "Electrical performances of RTV silicone rubber coatings in salt-fog and rotating wheel dip tests", Transactions of IEE Japan, Vol. 121-A, No. 4, pp. 324-331, 2001

61. Z. Jia, S. Fang, H. Gao, Z. Guan, L. Wang, Z. Xu, "Development of RTV silicone coatings in China: Overview and bibliography", IEEE Electrical Insulation Magazine, Vol. 24, No. 2, pp. 28-41, 2008

62. H. Deng, R. Hackam, E. A. Cherney, "Role of the size of particle of aluminatrihydrate filler on the life of RTV silicone rubber coating", IEEE Transactions on Power Delivery, Vol. 10, No. 2, pp. 10121024, 1995

63. S. H. Kim, R. Hackam, "Formation of silicone fluid at the surface of RTVsilicone rubber coating due to heat", Annual Report on Conference ofElectrical Insulation and Dielectric Phenomena, October 17-20, 1993, Pocono Manor, PA, USA, pp. 605-611

64. I. V. Tudose, M. Suchea, K. Siderakis, E. Thalassinakis, E. Koudoumas, "Comparative study on field collected samples of aged silicone rubber composite coatings for high voltage insulators", Acta Chemica Iasi, Vol.21, No. 2, pp. 93-106, 2013

65. X. Wei, Z. Jia, Z. Sun, Z. Guan, M. MacAlpine, "development of anti-icingcoatings applied to insulators in China", IEEE Electrical Insulation Magazine, Vol. 30, No. 2, pp. 42-50, 2014

66. D. Koenig, B. Mueller, "Neuere Erkenntisse ueber Vorgaenge auf feuchten Epoxidharz-Formstoff-Oberflaechen bei Hochspannungsbeanspruchung", Proceedings of 28 Internationale Wissenschaftliche Kolloquium, September1983, TH Ilmenau, Germany, Vortragsreihe "Elektrische Isoliertechnik", pp. 171-174

67. D. Koenig, I Quint, "recent investigations on the aging performance of wetepoxy resin post insulators stressed by surface partial discharges", Proceedingsof the $6^{\text {th }}$ International Symposium on High Voltage Engineering (ISH), August1989, New Orleans, USA, paper 47.12

68. S. Keim, D. Koenig, "Das Verhalten von Tropfen auf polymeren Isolierdtoff-oberflaechen bei Beanspruchung mit Wechselspannung", ETG Fachbericht,Vol. 76, ("Einfluss von Grenzflaechen auf die Lebensdauer elektrischer Isolierungen”), pp. 123-128, 1999

69. M. G. Danikas, "Surface phenomena on resin-type insulators under differentElectrical and non-electrical stresses in the early stage of ageing", Facta Universitatis, Vol. 13, No. 3, pp. 335-352, 2000

70. W. Zajac, J. Winkler, "Ageing of epoxide compositions for HV outdoor insulation: Diagnostic procedures and estimation criteria", Proceedings of the $6^{\text {th }}$ International Symposium on High Voltage Engineering (ISH), August 1989, New Orleans, USA, Paper 47.31

71. N. Yoshimura, M. Nishida, M. S. A. A. Hamman, "Tracking resistance oforganic insulating materials by Merry-go-round test method", Proceedings ofthe $6^{\text {th }}$ International Symposium on High Voltage Engineering (ISH), August 1989, New Orleans, USA, Paper 47.35

72. S. Ilhan, "Effects of RTV coating on the discharge characteristics of a suspension glass insulator", Electrica, Vol. 19, No. 2, pp. 173-181, 2019

73. S. Chandrasekar, R. Sarathi, M. G. Danikas, "Analysis of surface degradation ofsilicone rubber insulation due to tracking under different voltage profiles", Archiv fuer Elektrotechnik (Electrical Engineering), Vol. 89, pp. 489-501, 2007 
74. S. Kumara, M. Fernando, "Performance of outdoor insulators in tropicalConditions of Sri Lanka", IEEE Electrical Insulation Magazine, Vol. 36, No. 4, pp. 26-35, 2020

75. L. Xin, H. Jin, Y. Tu, Z. Yuan, Z. Lv, C. Wang, "Defect detection andcharacterization of RTV silicone rubber coating on insulator based on visible spectrum image", IEEE Transactions on Power Delivery, Vol. 35, No. 6, pp. 2734-2736, 2020

76. M. Bleszynski, S. Mann, M. Kumosa, "Visualizing polymer damage using hyperspectral imaging", Polymers, Vol. 12, No. 9, 13 pages, 2020 https://doi.org/10.3390/polym12092071

77. P. Vinod, B. M. A. Desai, R. Sarathi, S. Kornhuber, "Investigation on the electrical, thermal and mechanical properties of silicone rubber nanocomposites",IEEE Transactions on Dielectrics and Electrical Insulation, Vol. 26, No. 6, pp.1876-1884, 2019

78. K. Y. Lau, M. A. M. Piah, "Polymer nanocomposites in high voltage electrical insulation perspective: A review", Malaysian Polymer Journal, Vol. 6, No. 1, pp. 58-69, 2011

79. M. Amin, M. Ali, "Polymer nanocomposites for high voltage outdoor insulation applications", Reviews on Advanced Materials Science, Vol. 40, pp. 276-294,2015

80. M. Taghvaei, M. Sedighizadeh, N. Nayebpashaee, A. Sheikhi Fini, "Reliability assessment of RTV and nano-RTV-coated insulators concerning contamination severity", Electric Power Systems Research, Vol. 191, 12 pages, 2021 